\title{
Bed Planting System Promotes Crop Diversification for Improving Livelihoods in Western Uttar Pradesh, India
}

\section{R.K. Naresh ${ }^{1}$, R.S. Rathore ${ }^{2}$, Ashish Dwivedi ${ }^{1 *}$, Vineet Kumar ${ }^{3}$, Ashok Kumar ${ }^{3}$, Vivak Kumar ${ }^{4}$, Mukesh Kumar ${ }^{5}$, Amit Kumar ${ }^{6}$, Saurabh Tyagi ${ }^{1}$, Vineet Kumar ${ }^{1}$, Onkar Singh ${ }^{3}$ and R.K. Gupta ${ }^{7}$}

${ }^{1}$ Department of Agronomy, Sardar Vallabhbhai Patel University of Agriculture and Technology, Meerut-250110, (U.P), India

${ }^{2}$ Uttar Pradesh Council of Agricultural Research, Lucknow, India

${ }^{3}$ Department of Soil Science; Sardar Vallabhbhai Patel University of Agriculture and

Technology, Meerut-250110 (U.P), India

${ }^{4}$ Department of Agriculture Engineering; Sardar Vallabhbhai Patel University of Agriculture and Technology, Meerut-250110 (U.P), India

${ }^{5}$ Department of Horticulture, Sardar Vallabhbhai Patel University of Agriculture \&amp;

Technology, Meerut-250110 (U.P), India

${ }^{6}$ Krishi Vigyan Kendra, Tepla (Ambala)- Haryana, India

${ }^{7}$ Borlaug Institute for South Asia (BISA), New Delhi -110 012, India

*Corresponding author

\section{A B S T R A C T}

Keywords

MWCS-Maize, RWCS-Rice-

FIRB-Furrow irrigated raised bed, Crop diversification, Zero- tillage.

\section{Article Info}

Accepted:

24 January 2017

Available Online:

10 February 2017
The rice-wheat rotation is one of the world's largest agricultural production systems occupying about $85 \%$ of the cultivated land in the Indo-Gangetic Plains (IGP) and nearly one-sixth of the total geographical area of the sub continent. The system accounts for about one-third of the area of both rice and wheat grown in South Asia. Rice-wheat rotations produce more than $45 \%$ of the region's food and provide staple grains for nearly $42 \%$ of the total population of 1.3 billion of South Asia. Studies in past decade indicates that sustainability of rice-wheat system in IGP has been at risk mainly due to declining in groundwater levels, soil organic matter content and nutrient availability, increased soil salinization, incidence of pests and diseases. Practices commonly associated with sustainable management include accelerated adoption of resource conserving technologies (RCTs) and diversified crop rotations that enhance soil cover and fertility. In recent past a number of RCTs, like zero-tillage, bed planting, laser leveling, inter cropping of high value crops in the systems, has been introduced in the rice-wheat cropping system in IGP. The adoption of furrow irrigated raised bed (FIRB) planting technique at the farmer's fields is at initial stage in the region. In this paper importance of bed planting system promotes crop diversification for improving livelihoods in IGP has been described. 


\section{Introduction}

The paramount importance of ensuring food security of one billion plus strong population of the country that is growing at the pace of 1.8 per cent per annum cannot be undermined. During 1990-91 to 2003-04, the food grain production increased at a rate lower than the population growth. In the recent years, country's food grain production has been hovering around 210 million tones. According to the projections made by Planning Commission of India, the food grain requirement by the end of current decade will be about 235 million tones. This additional supply of 25 million tones may need to be sourced from domestic production system mainly through the production of wheat and rice in a short span of less than five years. In the context of the debate on food security versus food self-sufficiency, it is pertinent to note that India's food demand is for a very large population base which is about 16 per cent of world's population and it cannot afford to perpetually depend on imports.

Inter-year variability in food grain production added to additional demand may turn out to be about 20 per cent of nearly 130 million tones wheat and rice traded annually in the world. The release of area from rice-wheat rotation for crop diversification on account of sustainability is expected to be from high productivity regions of northwest India, where this issue has assumed greater significance. This will necessitate restoring the total acreage under these two crops at the current level of about 70 million hectares and augmenting the supply from low productivity regions through yield gains. Further, the additional demand for food security in the approach of crop diversification may be translating into additional demand for about six to seven million hectare acreage under food grains at the current level of productivity. The oilseeds and pulses account for about 45 million hectares. Augmentation of this area is considered to be important element of crop diversification strategy on account of substantial gap between domestic production supply and demand. Despite near stagnant productivity of these crops, low farm returns particularly from pulses, semi-arid cropping conditions with lesser flexibility of alternative crops leave little room for the area to be released for further diversification. About 14 million hectare area normally brought under cultivation of cotton, sugarcane and other fibre crops is otherwise integrated with their respective value chain. The 30 million hectare area normally sown under coarse cereals again in the semi-arid conditions is vulnerable to release acreage for high productivity food security options of wheat and rice with the expansion of irrigation facilities. If the import substitution of the order of 40 percent of domestic oilseeds production and 15 percent of domestic pulses production is translated into equivalent land resources, the country is faced with the deficit of about additional 15 million hectare arable land. Thus on land resource front, there are serious constraints for crop diversification.

The farmer's confidence on the market is another crucial aspect for sustainability of crop diversification. During the year 2004-05, there was noticeable shift in cropping pattern in some of the states such as in Gujarat in favour of cotton and in Rajasthan in favor of rapeseed and mustard. In both the cases, the price protection mechanism for the farmers in the production supply glut was found to be inadequate and the excellent crop production performance failed to get market response on price front. Such market imperfections act as disincentive to the approach of diversification. This brings to focus the role of market and other institutions to facilitate effective backward linkages, resource allocation, and infrastructure and risk management associated with commodities 
identified in the programme of crop diversification (Acharya, 2003).

The road map to crop diversification therefore require not only the synthesis of demand and supply of commodities in the existing cropping pattern vis a vis of those commodities to be promoted but that of improving the productivity and input use efficiency of crops like wheat and rice in different regions. Given that the flexibility to further crop diversification in the existing cropping pattern is constrained by the complexity of variable demand and supply of different commodities, it becomes imperative to give thrust to intercropping rather than crop displacement, wherever such feasibility exist. The strategy therefore would require multiple options (Hegde et al., 2003) such as land based or water based and vertical/ horizontal diversification encompassing sericulture and agro forestry. Moreover, the linked demand of fodder, that also is available as the byproduct of certain crops, needs to be taken note of.

The approach for crop diversification also requires to take note of its differentiated scope and adoptability by small and marginal farmers (Haque 1996). The problems confronted in this process are multidimensional. There are socio-economic constraints due to inadequate ability of small and marginal farmers to invest in crop and non-crop enterprises which require high investment of labor and inputs. These farmers are also unprepared to assume risks of adopting new agricultural activity with high opportunity cost of such diversification, particularly when certain crops may not sustain high value with augmentation of production and supply. Already there exists substantial technological gap in respect of important cereal crops in various region of the country and technological gains are confined to some regions only. Besides the technological gap, the access to technology by small farmers is another constraint. The skewed distribution of infrastructure such as road, transportation, market, post harvest handling, irrigation and power are impediments for both horizontal and vertical diversification. The problems related to agriculture are already addressed in the context of inadequate institutional support for delivery of credit, extension and other services. The institutional needs are bound to increase in crop diversification programme.

\section{Materials and Methods}

In any crop production technology, timeliness of agronomic and crop management practices particularly, the sowing operations are of great importance. To achieve timely sowing of crops in system ecology perspectives, research efforts have been made to develop resource conserving technologies (RCTs) so that the crop productivity could be enhanced and production costs and energy use is reduced. In past, several efforts had been made in on-station trials, but systematic efforts to involve farmers in the process of technology development and refinement were generally lacking or not in place. Accelerating adoption of zero till drills (for wheat ) and raised planters (for rice and wheat in the western and eastern district of UP project commissioned by the DASP together with other stakeholders provided the much needed opportunities for evaluating the new approach to technology generation and refinement and dissemination of the information in farmer participatory mode. Farmers were shown how Zero-till cum bed planting machine operates, and asking the manufacturers to make alterations in the machine design of the planter on the basis of farmers' feed back to serve as extensionists and resource per. Soon the practices became widely acceptable by wheat season and farmers began sons for the university. Then we focused on promotion and testing of other potentially useful 
practices as options for establishment of other crops. The experience enthused all, as it proved very cost effective to validate existing practices, generate newer ones and also reduce the long lag-period in technology generation and its adoption.

The main thrust of the experiments was to grow rice with less water, save on fuel consumption, improve productivity. These trials were designed to address issues related with efficient rain water use and receding water tables and eliminate the need for puddling which deteriorate soil structure and which is known to adversely affects the yield of crops succeeding rice in medium and finer textured soils. Pre-trial discussions revealed that puddling effects were short-lived and disappear as soon as soils develop cracks. Soil cracking was reported to be a general problem in rice culture in the area unless fields were kept continuously submerged. Once cracks develop farmers generally have to spend more fuel as it takes more time to complete irrigation due water by-pass.

On-farm investigations carried out on different tillage and crop establishment techniques involving permanent beds were conducted under farmer participatory researcher managed trials in western Uttar Pradesh during 2001, 2002 \& 2003, under the jurisdiction of Sardar Vallabhbhai Patel University of Agriculture \&Technology Meerut. Geographically Meerut is situated $29.01^{\circ}$ latitudes in the north and $77.75^{\circ}$ longitudes in the east and at altitude of $237 \mathrm{~m}$ above the sea level.

Climate and soils: The climate of the region is broadly classified as semi-arid subtropical, characterized by very hot summers and cold winters. The hottest months are May and June when the maximum temperature reaches 45$46^{\circ} \mathrm{C}$, whereas, during December and January, the coldest months of the year, the temperature often goes below $5^{0} \mathrm{C}$.The average annual rainfall is $863 \mathrm{~mm}, 75-80 \%$ of which is received through the northwest monsoon during July-September. In general the soils of the sites sandy loam in texture with medium fertility status. The soil texture at $0-30 \mathrm{~cm}$ is sandy loam and in lower profile $(30-170 \mathrm{~cm})$ it is fine sandy loam. The particle size distribution of $0-20 \mathrm{~cm}$ soil layer is $68.6 \%$ sand, $17.1 \%$ silt and $14.3 \%$ clay.

\section{Results and Discussion}

Crop diversification is intended to give a wider choice in the production of a variety of crops in a given area so as to expand production related activities on various crops and also to minimize risk. It is also critical to overcome the problems that are currently associated with the food security system of the IGP. Crop diversification in IGP is generally viewed as a shift from traditionally grown input inefficient crops to input efficient ones. The present scenario in IGP (food basket for the region) is dominated by monoculture of wheat after rice. Crop diversification proved to be paramount importance in mitigating the environmental problems arising on account of monoculture. Inclusion of certain crops in sequential and inter-cropping systems has been found to reduce some obnoxious weeds to a considerable extent, thereby reducing herbicides needs to a great extent in areas where such weeds have assumed alarming proportions. Legume intercropping in cereals grown with wider row spacing has been reported to reduce nitrate leaching (Yadav, 1981). Parallel multiple cropping (a system of growing two dissimilar growth habit crops with minimum competition) of sugarcane and black gram and that of pigeon pea and maize resulted in low NO3-N content in soil profile as compared to sole cropping (Yadav, 1982). As a crop management strategy to minimize $\mathrm{NO}_{3}-\mathrm{N}$ leaching, Singh et al., (1995) 
suggested for delaying large $\mathrm{N}$ applications until the crop can utilize it and avoiding irrigation when large amount of $\mathrm{NO}_{3}-\mathrm{N}$ is present in the root zone. Singh et al., (2005) reported that the post-wheat harvest $\mathrm{NO}_{3}-\mathrm{N}$ in soil profile beyond $45 \mathrm{~cm}$ depth was significantly greater under rice-wheat system than under pigeon pea-wheat system, suggesting that inclusion of pigeon pea may help in minimizing $\mathrm{NO}_{3}-\mathrm{N}$ leaching to deeper profile layers beyond root zone. They also recorded that with continuous rice-wheat cropping system, the bulk density (BD) of soil increased, especially in the $30-45 \mathrm{~cm}$ soil profile. Inclusion of pigeon pea in the system not only helped in maintaining the BD at initial level in the surface $(0-15 \mathrm{~cm})$ soil layers, but also in decreasing $(\mathrm{p}<0.05) \mathrm{BD}$ in sub surface layers (15-30 and 30-45 cm). Legume crops fix atmospheric $\mathrm{N}$ and enrich soil fertility, and could help to sustain the long-term productivity of cereal-based cropping systems. Depending on the soil and ecological stresses, the rice-wheat cropping system can be diversified using legumes as a substitute crop (Yadav et al., 1998).Results from the AICRP on Cropping Systems (AICRP-CS) show consistently better productivity from rice-pulse than rice-wheat systems (Hegde, 1992). The benefits of legumes in rotation are not solely due to biological nitrogen fixation, because increased nutrient availability, improved soil structure, reduced disease incidence and increased mycorrhizal colonization also occur (Wani et al., 1995).Soil organic carbon and available $\mathrm{N}, \mathrm{P}$ and $\mathrm{K}$ increased markedly, when the wheat in the rice-wheat cropping system was substituted with a legume (Hegde and Dwivedi, 1992). The experiments under AICRP-CS have shown that the benefits of growing legumes as a cash crop, green manure or as fodder depend on region, soil type, and legume species grown, all of which need to be accounted for when determining the optimal crop sequences for production and maintenance of soil fertility.

The conversion from conventional tillage to a reduced or zero tillage system with residue retention may require several crop cycles before potential advantage /disadvantages become apparent (Blevens et al., 1984). An additional advantage of bed planting becomes apparent when beds are 'permanent' that is, when they are maintained over the medium term and not broken down and re-formed for every crop. In this system, the crop is harvested and straw is left or burnt. Passing a shovel down the furrows reshapes the beds. The next crop (maize, pigeon pea, soybean, sunflower, cotton, etc.) can then be planted into the stubble in the same bed. Permanent beds combined with retaining all crop residues in the soil as stubble have the potential to increase both wheat and maize yield in Mexico (Agustin et al., 2000), and other crops in other parts of the globe. Research in farmers' fields has also shown that rice can be grown on beds, making this system feasible in the RW pattern. In context of increasing costs and scarce labor and increased competition in global market we have to evolve cost-effective agricultural technologies and through adoption of which growers can earn more profit. In this context conservation tillage or permanent bed planting will be quite useful. This technology besides reducing the cost of cultivation also helps in maintaining the soil productivity. In this system extensive tillage operations are performed for the preparation of beds for the first crop and thereafter for succeeding crops sowing and reshaping is done. The retention of crop residue will help in improving the physico-chemical and biological properties of the soil there by providing the deeper rooting and better soil, water and air relationships. Moreover, for intensive agriculture, there is a need to reduce the turnaround time for sowing of succeeding crops and use of permanent beds helps in reducing the turnaround time 
and thereby increasing the cropping intensity. For rice-wheat system, land preparation assumes significance. Fine soil tilth, similar to conventional field preparation, is mandatory for adopting FIRB system. For other wheatbased systems like cotton-wheat, soybeanwheat and maize-wheat etc both the crops can be raised on the same beds involving single tillage operation using bed planter. Some of the other sequences that can be taken on permanent beds are wheat-moong beansoyabean, wheat- moong bean- pigeon pea, pea-wheat-maize, mustard-soybean, chickpeasoybean. Sayre and Hobbs, (2004) pointed out that there is need for some implement modification for permanent bed planting with residue retention. For residue management disc coulters could be attached ahead of the furrow openers. Sayre and Hobbs (2004) also reported continuous crop residue retention has had, the higher average yield closely followed by conventional tillage with residue incorporation, then the permanent bed burning. Naresh et al., (2005) reported a notable increase in economic yield of maize being 23.5 and $32.2 \%$ with furrow irrigated raised bed (FIRB) planting $(5.75 \mathrm{t}$ ha $\left.{ }^{1}\right)$ compared to flat no-till(4.15 $\left.\mathrm{t} \mathrm{ha}^{-1}\right)$ and conventional till $\left(3.90 \mathrm{t} \mathrm{ha}^{-1}\right)$ planting systems, respectively(Table 1). Whereas, the productivity of wheat was higher by 5.2 and $20.8 \%$, respectively under flat no-till $(5.10 \mathrm{t}$ $\left.\mathrm{ha}^{-1}\right)$ compared to no-till FIRB (5.86 $\left.\mathrm{t} \mathrm{ha}^{-1}\right)$ and flat conventional till planting $\left(4.85 \mathrm{t} \mathrm{ha}^{-1}\right)$. Further, the water productivity (kg grain $\mathrm{m}^{-3}$ water) of either crop of maize and wheat was remarkably higher in FIRB planting (2.42 and 2.20) followed by no-till (1.53 and 1.96) and the lowest (1.16 and 1.29) in conventional till system. The economic analysis revealed that net profit $\left(\mathrm{Rs} \mathrm{ha}^{-1}\right)$ was more in no-till $(20,050$ and 23,300) followed by FIRB wide (19575 and 22650) and least in conventional-till (13790 and 17550), respectively for maize and wheat (Table 1).
The permanent raised bed cropping system gave improved water, $\mathrm{N} \& \mathrm{P}$ economies, energy savings, greater timelines of operations and improved soil structure of the crop zone due to reduced soil compaction. The permanent beds with residue retention had lower $\mathrm{Na}$ content and electrical conductivity but higher organic matter and total $\mathrm{N}$ levels compared to tilled or residue burning. The higher $\mathrm{C}$ and $\mathrm{N}$ levels indicates better soil health and thereby sustainability. Permanent beds with residue retention also result in lower run off and soil erosion, and better soil structure in $0-15 \mathrm{~cm}$ depth (Hulugalle et al., 2002). From above discussions it can be inferred that permanent bed technology offers an opportunity for higher production at reduced cost in a sustainable manner.

\section{Prospects of Raised Bed planting system for crop diversification in IGP}

There is increasing concern about the sustainability of high input, intensively cropped; cereal dominated cropping systems in IGP. There is evidence of system productivity stagnation, nutrient and water imbalance. The ameliorative effect of including legumes in such continuous cereal dominated crops and cropping systems has long been known but, over time, legume crops have generally declined in importance with crop intensification. This is a consequence of low yield potential of legumes as compared to cereals and their susceptibility to many abiotic and biotic stresses. Consequently, legumes were perceived as risky crops, especially by resource poor farmers. However, recent advances in management techniques of legumes do raise the feasibility of their greater use in cereal-dominated systems, so as to increase crop diversification and contribute to system sustainability. The diversified agro-climatic, biophysical and socio economic conditions of IGP suited to 
different crops and cropping systems have wide scope for diversification of rice-wheat cropping system. The diversification and intensification for sustained productivity of crops and cropping systems in IGP have in practice especially with the development of new generation multi crop bed planters. The FIRB planting technique provides an opportunity for crop diversity through inclusion of various crops as well as feasibility of inter or relay cropping thereby leading to resource efficient cropping systems. Pigeon pea, the most important wet season grain legume crop in south Asia has shown potential for rice crop diversification in IGP. The introduction of extra short duration (ESD) pigeon pea (ICPL- 88039) and FIRB planting technique in the region has shown tremendous potential for increasing the water productivity and economic growth of the farmers with the limited resources. The results of on-farm trials in IGP revealed a marked increase in water productivity and net profit under pigeon pea-based system compared to rice based system (Naresh and Singh, 2008). They reported that the water productivity and net profit was further increased with FIRB planting technique compared to flat planting technique (Table 2).

The winter legumes like chickpea has been disappeared from the cropping systems due the intensive irrigated cereal and sugarcane dominated production systems during last 2-3 decades. In view of the sustained productivity and nutritional security, the researchers have advocated the inclusion of winter legumes in the cropping systems in this region. Chickpea, the potential winter legume crop of the region have been reintroduced with the availability of the new crop management techniques in general and raised bed planting technique in particular. The results of the on-station and on-farm trials in western IGP (Naresh and Singh, 2008) revealed that under flat planting technique, the water productivity and profitability of chickpea was less than the wheat but, it was improved with the raised bed planting technique (Table 3 ).

The effect of rice crop diversification as with maize on the succeeding wheat shown a remarkable increase in the grain and water productivity and profitability of wheat (Table 4).

The effect was much more pronounced under FIRB planting technique than the flat planting systems (Naresh and Singh 2008). They also reported that the FIRB planting technique have potential for intercropping of high value cash crops with the row crops like maize during the winter season. They reported a marked increase in net income of the farmers of western Uttar Pradesh (India) through adoption winter maize based high value inter cropping systems under FIRB planting technique (Table 5). In another study at S.V.P U A \& T, Meerut (India) they reported that maize intercropped with high value crops viz., vegetable and flower crops gave higher net returns than sole maize. Further, the gladiolus intercropping in maize fetched three time higher net returns compared to sole maize (Table 5).

Gladiolus is a high market value crop and is feasible to be grown in peri-urban areas. Due to good transportation facilities intercropping of gladiolus and vegetables with maize in FIRB planting technique is a better substitute for higher farm income in the peri urban areas. With the introduction and popularization of FIRB planting technique, farmers in Indian IGP are accepting a new practice of simultaneous cropping of wheat and sugarcane. In this technique, wheat is grown on beds and sugarcane in furrows. In some areas generally farmer's plant sugarcane after harvest of wheat crop (May) and the yield of late planted sugarcane is very low due to poor germination, higher weed population and shorter tillering period. 
Autumn sugarcane gave 25 per cent higher cane yield and higher sugar recovery than spring planted sugarcane. So to achieve higher cane yield and better returns, autumn planted cane needs special attention. Since there is a loss of one rabi crop if sole autumn sugarcane is planted, by inter cropping system, both wheat and sugarcane can be grown successfully. Samar Singh et al., (2002) reported that in this system sugarcane had no adverse effect on wheat yield, since sugarcane remain dormant during winter months and does not compete with wheat and a productivity level of $5.84 \mathrm{t} \mathrm{ha}^{-1}$ in wheat and $95 \mathrm{t}^{\text {cane }} \mathrm{ha}^{-1}$ was recorded with sugarcane + wheat system in FIRB technique (Table -6).

\section{Raised bed planting system and Water management}

Raised bed planting, being a water efficient technology may prove a boon for farmers of dry land regions, where water is top priority. The hydrology of the flat and bed system is different. In bed water moves originally furrow to furrow into beds and also upward into bed though evaporation \& capillary action. In furrow water moves down ward by gravity. The downward movement is greatly reduced under permanent bed system. Therefore in light soil may be useful in avoiding the nutrient \& water losses through deep percolation. The upward movement of water into bed may also cause accumulation of salts in the surface \& and may affect crop growth and needs special attention. In light textured soils having low water holding capacity and higher infiltration rates generally irrigation through flooding method have high water losses in the form of evaporation and seepage resulting into low water, nutrient and other input use efficiencies and it also consumes lot of time. In raised bed planting systems due to compaction of soil by tractor tyre in furrows causes faster movement of water and also lesser area to be covered for irrigation (40\%).So, small quantity of water can be applied over large area through bed planting and depending up on soil type water saving ranges from 20 to $40 \%$. Bed planting system leads to about $40 \%$ saving of diesel, time and water requirement. Moreno et al., (1993) and Sayre (2000) have reported increased water use efficiency and $35 \%$ reduction in irrigation water requirement in wheat grown under raised bed planting systems in Mexico and improvement in yield by $10 \%$ with irrigation application in furrows as compared to flood irrigation .Similarly, Moreno et al., (1993) also reported higher water productivity, better utilization of solar radiation, less weed competition and crop lodging. The additional advantage of the system is that additional irrigation at grain filling can be made which generally results in lodging under flat system.

Table.1 Effect of double no -till flat and raised bed planting system on crop yield, water productivity and profitability of maize and wheat

\begin{tabular}{|l|c|c|c|c|c|c|}
\hline \multirow{2}{*}{$\begin{array}{l}\text { Crop } \\
\text { establishment }\end{array}$} & \multicolumn{2}{|c|}{ Grain yield t ha } & \multicolumn{2}{c|}{ Water productivity(kg grain $\mathbf{~ m}^{-\mathbf{1}}$} & \multicolumn{2}{c|}{ Net profit(Rs ha $\mathbf{~}^{\mathbf{- 1}}$ ) } \\
\cline { 2 - 7 } & Maize & Wheat & Maize & Wheat & Maize & Wheat \\
\hline No- till flat & 4.15 & 5.10 & 1.53 & 1.96 & 20050 & 23300 \\
\hline FIRB narrow & 5.10 & 5.32 & 1.87 & 1.77 & 16910 & 20950 \\
\hline FIRB wide & 5.75 & 5.86 & 2.42 & 2.20 & 19575 & 22650 \\
\hline Conventional & 3.90 & 4.85 & 1.16 & 1.29 & 13790 & 17550 \\
\hline Average & 4.73 & 5.23 & 1.75 & 1.81 & 17581.25 & 21112.50 \\
\hline
\end{tabular}


Table.2 Effect of crop establishment methods on crop yield, water productivity and profitability of rice and pigeonpea

\begin{tabular}{|l|c|c|c|c|c|c|}
\hline \multirow{2}{*}{$\begin{array}{l}\text { Crop } \\
\text { establishment }\end{array}$} & \multicolumn{2}{|c|}{ Grain yield t ha } & \multicolumn{2}{c|}{ Water productivity $\left(\mathbf{k g}_{\text {grain }} \mathbf{~}^{-\mathbf{3}}\right.$ water $)$} & \multicolumn{2}{c|}{ Net profit $\left(\mathbf{R s ~ h a}^{\mathbf{- 1}}\right)$} \\
\cline { 2 - 7 } & Rice & Pigeonpea & Rice & Pigeonpea & Rice & Pigeonpea \\
\hline No- till flat & 3.85 & 1.90 & 0.58 & 1.27 & 18820 & 25400 \\
\hline FIRB narrow & 4.12 & 2.24 & 0.59 & 1.86 & 19225 & 29200 \\
\hline FIRB wide & 5.18 & 2.76 & 0.67 & 2.41 & 22630 & 37200 \\
\hline Conventional & 5.35 & 1.78 & 0.57 & 1.54 & 20725 & 23200 \\
\hline Average & 4.63 & 2.17 & 0.60 & 1.17 & 20350 & 28750 \\
\hline
\end{tabular}

Table.3 Effect of crop establishment methods on crop yield, water productivity and profitability of wheat and chickpea

\begin{tabular}{|c|c|c|c|c|c|c|}
\hline \multirow{2}{*}{$\begin{array}{c}\text { Crop } \\
\text { establishment }\end{array}$} & \multicolumn{2}{|c|}{ Grain yield $\mathbf{t}$ ha $^{-1}$} & \multicolumn{2}{|c|}{ Water productivity(kg grain $\mathrm{m}^{-3}$ water) } & \multicolumn{2}{|c|}{ Net profit(Rs ha $\left.{ }^{-1}\right)$} \\
\hline & Wheat & Chickpea & Wheat & Chickpea & Wheat & Chickpea \\
\hline No- till flat & 5.1 & 1.5 & 1.74 & 0.88 & 22450 & 11300 \\
\hline FIRB narrow & 5.2 & 1.9 & 1.98 & 1.37 & 25400 & 15800 \\
\hline FIRB wide & 5.7 & 2.3 & 2.17 & 1.87 & 29650 & 18800 \\
\hline Conventional & 4.9 & 1.4 & 1.56 & 0.74 & 20450 & 9300 \\
\hline Average & 5.23 & 1.78 & 1.86 & 1.22 & 24487.50 & 13800.00 \\
\hline
\end{tabular}

Table.4 Comparative performance of wheat on permanent beds in rice -wheat and maize -wheat cropping system

\begin{tabular}{|l|c|c|c|c|c|c|}
\hline \multirow{2}{*}{$\begin{array}{c}\text { Crop } \\
\text { establishment }\end{array}$} & \multicolumn{2}{|c|}{ Wheat yield t ha } & \multicolumn{2}{c|}{$\begin{array}{c}\text { Water productivity(kg grain } \mathbf{~ m}^{-\mathbf{3}} \\
\text { water) }\end{array}$} & \multicolumn{2}{c|}{ Net profit $\left(\mathrm{Rs} \mathrm{ha}^{\mathbf{- 1}}\right)$} \\
\cline { 2 - 7 } & RWCS & MWCS & RWCS & MWCS & RWCS & MWCS \\
\hline No- till flat & 4.78 & 5.34 & 1.47 & 1.94 & 21800 & 26150 \\
\hline FIRB narrow & 4.43 & 5.29 & 1.73 & 2.12 & 20450 & 25475 \\
\hline FIRB wide & 5.16 & 5.65 & 1.98 & 2.20 & 24700 & 29850 \\
\hline Conventional & 4.87 & 5.14 & 1.21 & 1.43 & 17650 & 22500 \\
\hline Average & 4.81 & 5.36 & 1.60 & 1.92 & 21150 & 25993.75 \\
\hline
\end{tabular}

Table.5 Wheat crop diversification opportunities through winter maize based high value intercropping systems in FIRB planting technique in western Uttar Pradesh

\begin{tabular}{|c|c|c|c|c|c|}
\hline \multirow[t]{2}{*}{ Cropping patterns } & \multicolumn{2}{|c|}{ Yield( t/ha) } & \multicolumn{3}{|c|}{ Net returns $\left(\mathrm{Rs} \mathrm{ha}^{-1}\right)$} \\
\hline & Maize & Intercrop & Maize & Intercrop & System \\
\hline Maize sole & 5.65 & 0 & 17784 & - & 17784 \\
\hline Wheat sole & 4.95 & 0 & 24570 & - & 24570 \\
\hline Maize+ coriander ${ }^{1}$ & 4.15 & 3.4 & 13063 & 34170 & 47233 \\
\hline Maize+ potato & 4.75 & 8.5 & 14951 & 32853 & 47803 \\
\hline Maize+ onion ${ }^{1}$ & 4.60 & 3.6 & 14479 & 12852 & 27331 \\
\hline Maize+ lady finger & 4.30 & 5.6 & 13535 & 44800 & 58335 \\
\hline Maize+ tomato & 5.25 & 1.8 & 16525 & 18000 & 34525 \\
\hline Maize+ gladiolus ${ }^{2}$ & 4.50 & 17650.0 & 14164 & 88250 & 102414 \\
\hline Maize+ cabbage & 5.40 & 4.7 & 16997 & 37600 & 54597 \\
\hline Maize+vegetable peas & 4.80 & 2.8 & 15108 & 30800 & 45908 \\
\hline
\end{tabular}

${ }^{1}$ Green onion and green leaves; ${ }^{2}$ Number of flowering stems 
Table.6 Effect of crop diversification opportunities through FIRB system on productivity of sugarcane based production system

\begin{tabular}{|l|r|l|}
\hline \multirow{2}{*}{ Treatment } & \multicolumn{2}{|c|}{ Yield(t ha ${ }^{-1}$ ) } \\
\cline { 2 - 3 } & Wheat & \multicolumn{1}{c|}{ Sugarcane } \\
\hline Conventional wheat & 5.57 & - \\
\hline Bed planted wheat without intercropping & 6.00 & - \\
\hline Wheat planted on beds intercropped with sugarcane in furrows & 5.84 & 94.5 \\
\hline Spring planted sugarcane & -78.8 & \\
\hline Summer planted sugarcane & -60.0 & \\
\hline
\end{tabular}

This practice will lead to yield improvement particularly the thousand-grain weight. Raised bed not only facilitate in efficient water usage but also drainage. Therefore, it helps in improving the yield under both dry and excessive wet conditions. Ahmad et al., (1998) in Pakistan conducted three years trials involving three water management practices considering depth and frequency of irrigation water i.e. irrigation at 50 per cent depletion of available water (DAW), irrigation at 25 per cent DAW and irrigation at 50 per cent DAW with leaching fraction of 0.2 and two planting practices i.e. bed sowing and plain sowing. The result showed that bed planting proved better than plain planting for one-year reuse of drainage water irrigation. The combination of bed planting and irrigation with drainage at 50 per cent DAW with a leaching fraction of 0.2 gave higher grain yield. Further modified irrigation techniques, alternate furrow irrigation can be adopted in highly water scarce area. This alternative irrigation method helps to reduce water loss through runoff, deep percolation and evaporation.

In conclusion, there is an urgent need to investigate alternate cropping systems to overcome the major productivity constraints, resource depletion, and pollution problems of existing systems. The predominant cropping systems in IGP have started exhibiting signs of stress. Diversification of crops and cropping systems that have high water productivity, profitability and long-term sustainability with the availability of modern management techniques may prove a better alternative in this respect. Water is becoming a scarce resource for crop production and promoting the diversification with intensification using water, wise technologies has become mandatory for sustainability. The intercropping of legumes, vegetables and other high value crops with the availability of new crop establishment techniques i.e. FIRBS is the way towards nutritional security and economic growth of the farmers large number of technological optional for crop diversification are available which need kind attention of the extension agencies for their dissemination and acceleration of adoption at farm level.

\section{References}

Acharya, S.S.2003. "Crop Diversification in Indian Agriculture", Agricultural Situation in India, Vol. LX, No.5 August 2003, New Delhi.

Agustin, L.O., Kennyth, D.S. and Charles, A.F.2000.Wheat and Maize yield in response to straw management and nitrogen under a bed planting system. Agron. J., 92: 295-302.

Ahmad, A., Mahmood, N.and Akhtar, B.1998.Effect of different depths of irrigation on the grain yield of promising late sown wheat cultivars. Rachis Publ., 16: 77-80.

Blevins, R.L., Smith, M.S. and Thomas, G.W.1984.Changes in soil properties under no-tillage. In No-Tillage AgriculturePrinciples and Practices Phillips S.H., Eds: Van Nostrand Rheinhold Company. New York, 190-320.

Balasubramanian, V., Ladha, J.K., Gupta, R.K., Naresh, R.K., Mahela, R.S., Singh, B.and Singh, Y.2003.Technology options for rice 
in rice-wheat system in south Asia.P.115118.In J.K.Ladha et al., (ed.).Improving the productivity and sustainability of ricewheat systems: Issues and impact.ASA Spec.Pub.65ASA, CSSA, and SSSA, Madison, WI.

Gupta, R.K., Naresh, R.K., Hobbs, P.R. and Ladha, J.K.2002.Adopting Conservation Agriculture in Rice-Wheat Systems of the Indo-Gangetic Plains- New Opportunities for Saving on Water. Paper presented at the "Water wise rice production workshop", 510 April 2002, IRRI, Philippines

Haque.T.1996. "Small Farms Diversification: Problems and Prospects" Proceedings of National Workshop on Small Farm Diversification: Problems and Prospects, Ed.T. Haque, National Centre for Agricultural Economics and Policy Research 1996.

Hegde, D.M., S. Prakash Tiwari and M.Rai.2003."Crop Diversification is Indian Agriculture" Agricultural Situation in India, Vol.LX, No.5 August 2003, New Delhi.

Yadav, R.L.1982.Minimizing nitrate-nitrogen leaching by parallel multiple cropping in long duration row crops. Experimental Agri., 18: 37-42.

Moreon, O., M. Salazar, M. Tamayo and J.Martinez.1993.Technologia para la produccion de trigo en surcos. Foll.Tecn..22. Sarh. Inifap. Cd. Obregon. Sonara, Mexico.

Sayre, K.D.2000.Effects of tillage, crop residue retention and nitrogen management on the performance of bed-planted, furrowirrigated spring wheat in northwest Mexico.Proc.15th Conf. Int. Soil Tillage Res.Org.27 July 2000.Fort Worth, Texas, USA.

Sayre, K.D. and P.R.Hobbs.2004.The Raised- Bed System of Cultivation for Irrigated
Production Conditions. In Sustainable Agriculture and the International RiceWheat System, Lal et al., (Eds) PP 337-355

Sharma, P.K., Bhushan Lav, ladha, J.k., Naresh, R.K., Gupta, R.K., Balasubramanian, B.V., and Bhouman, B.A.M.2002.Crop-water relations in rice-wheat cropping under different tillage systems and watermanagement practices in a marginally sodic, medium-textured soil. In "Waterwise Rice Production' (Eds, Bouman BAM, Hengsdijk H, Hardy B, Bindraban B, Toung TP, and Ladha JK)) pp.223235.Proceedings of the International Workshop on Water-wise Rice Production, 8-11,April 2002, Los Banos, Philippines (IRRI, Los Banos, Philippines).

Singh, R., Gajri, P.R., Gill, K.S. and Khera, R.1995.Puddling intensity and nitrogen use efficiency of rice (Oryza sativa) in a sandy loam soil of Punjab. Indian J.Agri., 54: 65(10): 749-751.

Wani, S.P., Rupela, O.P.\& Lee, K.K.1995.Sustainable agriculture in the semi-arid tropics through biological nitrogen fixation in grain legumes. Plant and Soil, 174: 29-49.

Yadav, R.L.1981.Intercropping pigeonpea to conserve fertilizer nitrogen in maize and its residual effect on sugarcane. Experimental Agri., 17: 311-315.

Yadav, R.L., Dwivedi, B.S. Gangwar, K.S.\& Prasad, K.1998.Overview and prospects for enhancing residual benefits of legumes in rice and wheat cropping systems in India. In Residual Effects of Legumes in Rice and Wheat Cropping Systems of the IndoGangetci Plain (eds J.V.D.K. Kumar Rao, C. Johansen \&T.J. Rego), pp, 207225.Patancheru: International Crops Research Institute for the Semi-arid Tropics.

\section{How to cite this article:}

Naresh, R.K., R.S. Rathore, Ashish Dwivedi, Vineet Kumar, Ashok Kumar, Vivak Kumar, Mukesh Kumar, Amit Kumar, Saurabh Tyagi, Vineet Kumar, Onkar Singh and Gupta, R.K. 2017. Bed Planting System Promotes Crop Diversification for Improving Livelihoods in Western Uttar Pradesh, India.Int.J.Curr.Microbiol.App.Sci.6(2): 1580-1590.

doi: http://dx.doi.org/10.20546/ijcmas.2017.602.177 